\title{
Association of RAS mutations with early progression after first-line systemic therapy in patients with initially unresectable colorectal cancer liver metastasis
}

\section{Di Cao}

Sun Yat-sen University Cancer Center https://orcid.org/0000-0001-7406-8938

\section{Cong Li}

Sun Yat-sen University Cancer Center

Chi Zhou

Sun Yat-sen University Cancer Center

Weili Zhang

Sun Yat-sen University Cancer Center

Zhenhai Lu

Sun Yat-sen University Cancer Center

\section{Zhizhong Pan}

Sun Yat-sen University Cancer Center

\section{Gong Chen}

Sun Yat-sen University Cancer Center

Jianhong Peng ( $\nabla$ pengjh@sysucc.org.cn )

Sun Yat-sen University Cancer Center https://orcid.org/0000-0002-5198-2919

\section{Primary research}

Keywords: Colorectal cancer, Initially unresectable, RAS gene, Early progression

Posted Date: November 1st, 2021

DOI: https://doi.org/10.21203/rs.3.rs-1016958/v1

License: (c) (i) This work is licensed under a Creative Commons Attribution 4.0 International License. Read Full License 


\section{Abstract \\ Purpose}

Patients with initially unresectable colorectal cancer with liver metastases (IU-CRLM) need to undergo first-line systemic therapy with the aid of chemotherapy. However, the driver gene attributed to early progression in IU-CRLM patients after first-line systemic therapy remains unclear. Our study explored the RAS mutation status related to early progression in IU-CRLM patients.

\section{Methods}

A total of 193 IU-CRLM patients with RAS status detection were retrospectively enrolled from December 2012 to January 2020. We defined early progression as tumour progression within 6 months after firstline systemic therapy. Univariate and multivariate logistic regression for early progression were implemented to identify the risk factors.

\section{Results}

RAS mutations were found in 51 (26.0\%) IU-CRLM patients. A total of 107 (55.4\%) patients were confirmed to have early progression after first-line systemic therapy. RAS mutation was significantly related to early disease progression $(66.7 \%$ vs. $49.3 \%, P=0.033)$. Logistic analysis results showed that RAS mutation ( $\mathrm{OR}=2.962,95 \% \mathrm{Cl} 1.354-6.478, \mathrm{P}=0.007)$ was an independent risk factor for early disease progression.

\section{Conclusions}

Mutated RAS was an important risk factor for early progression in IU-CRLM patients after first-line systemic therapy.

\section{Background}

Distant metastases from colorectal cancer (CRC) are a leading cause of cancer-related death in the United States and China ${ }^{[1,2]}$. Liver metastases are commonly found in more than half of patients with $\mathrm{CRC}$, and liver resection has been recognized as the most crucial curative measure for patients with colorectal liver metastasis (CRLM) ${ }^{[3]}$. However, nearly $80 \%-85 \%$ of patients with CRLM are considered unresectable at the time of initial diagnosis ${ }^{[4,5]}$. Among these patients, those who received systemic conversion chemotherapy were found to have better long-term survival outcomes than patients treated with chemotherapy alone and could become eligible for surgical resection thereafter ${ }^{[6]}$. Moreover, evidence suggests that complete resection of the primary tumour and liver metastases can confer a 
nearly $15 \%$ higher chance of long-term survival for initially unresectable CRLM (IU-CRLM) patients than for those without complete resection ${ }^{[7]}$. At present, the conversion rate in IU-CRLM varies between $22 \%$ and $57 \%{ }^{[8]}$. Nevertheless, only $28 \%$ of IU-CRLM patients who receive R0 resection can achieve long-term survival (over 5 years) ${ }^{[9]}$. One of the most important factors of poor survival after treatment is disease progression, which occurs in approximately $50 \%$ of all patients, among whom approximately $30 \%$ develop early disease progression. Patients with early progression have extremely poor survival ${ }^{[10,11]}$. Therefore, it is necessary to identify risk factors for early progression that can be used to guide clinical decisions.

There are various risk clinicopathological factors that have been associated with poor prognosis, such as poorly differentiated primary tumours, metastatic tumour size over $5 \mathrm{~cm}$, positive resection margins, and high preoperative carcinoembryonic antigen (CEA) levels ${ }^{[12-15]}$. Distant metastasis is mainly caused by a variety of gene mutations, and the epidermal growth factor receptor (EGFR) signalling pathway activated by KRAS mutation has been found to be crucial for CRC progression and metastasis ${ }^{[16-19]}$. There have been several studies reporting RAS mutation as an independent predictor of poor prognosis in patients with CRLM undergoing liver resection. ${ }^{[16,20-22]}$ Our previous study showed that patients with KRAS mutations had worse progression-free survival (PFS) than those with wild-type KRAS (4.9 vs. 13.1 months, $\mathrm{P}=0.017) .{ }^{[10]}$ However, whether there is a correlation between RAS mutation and early progression after first-line systemic therapy in IU-CRLM patients remains unclear. Elucidating the relationship between RAS mutation and early progression in CRLM patients can help to establish and optimize therapeutic strategies.

To address this issue, we performed this retrospective study. First, we describe the RAS mutation spectrum of IU-CRLM patients. Second, we focus on identifying the relationships among RAS mutation, conversion therapy outcomes and early disease progression.

\section{Methods}

\section{Source of data}

A total of 193 patients diagnosed with CRLM metastases who underwent first-line treatment were retrospectively sourced from the Sun Yat-sen University Center between December 2012 and January 2020. All patients in both cohorts satisfied the following inclusion criteria: (1) histologically confirmed colorectal adenocarcinoma, (2) metastases limited to the liver, (3) initially unresectable liver metastases, (4) no previous liver resection or interventional therapy, (5) available information on RAS status, and (6) an explicit conversion outcome. Informed consent for the use of the imaging and clinical data was obtained from the patients before first-line treatment. All procedures were performed based on the Declaration of Helsinki. The study was approved by the Institutional Research Ethics Committee of Sun Yat-sen University Cancer Center (approval number: B2020-309-01).

\section{Clinical parameter assessment}


The TNM stages of primary tumours were classified according to the American Joint Committee on Cancer (AJCC) eight edition criteria. The pre-treatment characteristics of liver metastases were assessed by enhanced abdominal computed tomography (CT) and nuclear magnetic resonance imaging (MRI), including tumour numbers, the size of the largest tumour, and distribution. The CEA and cancer antigen (CA) 19-9 levels were measured before first-line treatment was administered.

\section{RAS mutation profiling}

RAS mutations were assessed in DNA from resected primary tumour specimens of CRLM. A routine polymerase chain reaction-based primer extension assay was performed to screen for mutations in KRAS codons 12, 1361 and 146 and NRAS codons 12, 13, and 61 in all patients. Mutations in the various codons of KRAS and NRAS were reported and analysed together as RAS mutations.

\section{Treatment outcomes}

The treatment strategy and operability of the liver metastases of each patient were determined based on the final agreement of the multidisciplinary team (MDT), including staff from the Department of Colorectal Surgery, Hepatobiliary Surgery, Medical Oncology, Medical Imaging, and Invasive Technology. Tumour response or progression after first-line treatment was determined according to the Response Evaluation Criteria in Solid Tumors (RECIST) version $1.1^{[23]}$. Successful conversion was defined as liver metastases deemed to be resectable after first-line systemic treatment, and patients achieving no evidence of disease (NED) status contributed by local treatment, including surgery and radiofrequency ablation (RFA), while conversion failure was defined as liver metastases remaining unresectable after first-line systemic treatment and patients failing to receive curative local treatment. According to previous data, early progression was defined as disease recurrence or death within 6 months after first-line systemic treatment ${ }^{[10,24-27]}$.

\section{Statistical analysis}

The statistical analyses were performed using IBM SPSS Statistics 26 software (IBM, NY, USA) and GraphPad Prism version 6.01 (GraphPad Software, Inc., USA). Variables with a value of $p<0.05$ in univariate analysis were further assessed with a logistic regression model for multivariate analysis to identify independent factors associated with early progression, and odds ratios (ORs) and 95\% confidence intervals (Cls) were subsequently calculated.

\section{Results}

\section{Patient characteristics and systemic therapy}

The demographic and clinicopathological characteristics and treatment approaches of the 193 patients are summarized in Table 1. The median age of the patients was 54.5 years (range 26-80 years), comprising $141(73.1 \%)$ males and 52 (26.9\%) females. The median diameter of the largest liver metastasis was $6 \mathrm{~cm}$ (range 1-18 cm), and the median number of liver metastases was 8 (range 1-100). 
Regarding first-line therapy, 128 (66.3\%) patients received the FOLFOX regimen, 18 (9.3\%) patients received the FOLFIRI regimen, 34 (17.6\%) patients received the FOLFOXIRI regimen, and $13(6.7 \%)$ patients received hepatic arterial infusion (HAl) chemotherapy. In addition, a total of 152 patients received targeted therapy; 53 (34.9\%) received bevacizumab, and 99 (65.1\%) had received cetuximab. The median chemotherapy cycle number was 8 (range 2-17). Among the 193 patients, 85 patients had a successful conversion therapy outcome, while 108 patients experienced conversion therapy failure. The success rate of conversion therapy was $44.0 \%$. Of these, 46 patients underwent hepatectomy alone, and 39 patients underwent hepatectomy combined with RFA. After first-line chemotherapy, 96 (49.7\%) patients achieved a partial response (PR), 50 (25.9\%) patients achieved stable disease (SD), and 47 (24.4\%) patients achieved progressive disease (PD). During the median follow-up time of 19.4 months (range 2.7-91.9), tumour progression occurred in 169 (87.6\%) patients at the end of follow-up, including 104 (53.9\%) patients with early disease progression. 
Table 1

Clinical characteristics of the total patients.

\begin{tabular}{|c|c|}
\hline Variables & Total patients $(n=193)$ \\
\hline Median age (range) - years & $54.5(26-80)$ \\
\hline Gender - no. (\%) & $141(73.1)$ \\
\hline \multicolumn{2}{|l|}{ Male } \\
\hline Female & $52(26.9)$ \\
\hline \multicolumn{2}{|c|}{ Primary tumor location ${ }^{a}$ - no. $(\%)$} \\
\hline Colon & $132(69.4)$ \\
\hline Rectum & $58(30.5)$ \\
\hline \multicolumn{2}{|c|}{ Primary tumor differentiation ${ }^{\mathrm{b}}$ - no. (\%) } \\
\hline Well or moderate & $144(81.4)$ \\
\hline Poor & $33(18.6)$ \\
\hline \multicolumn{2}{|l|}{ Clinical T staging - no. (\%) } \\
\hline T1-T3 & $97(50.3)$ \\
\hline $\mathrm{T} 4$ & $96(49.7)$ \\
\hline \multicolumn{2}{|l|}{ Clinical N staging - no. (\%) } \\
\hline No & $28(14.5)$ \\
\hline N1-N2 & $165(85.5)$ \\
\hline \multicolumn{2}{|c|}{ Timing of liver metastases - no. (\%) } \\
\hline Synchronous & $180(93.3)$ \\
\hline Metachronous & $13(6.7)$ \\
\hline \multicolumn{2}{|c|}{ Number of liver metastases - no. (\%) } \\
\hline$\leq 10$ & $121(62.7)$ \\
\hline$>10$ & $72(37.3)$ \\
\hline \multicolumn{2}{|c|}{ Maximum size of liver metastases - no. (\%) } \\
\hline$\leq 6 \mathrm{~cm}$ & $113(58.5)$ \\
\hline$>6 \mathrm{~cm}$ & $80(41.5)$ \\
\hline Distribution of liver metasta & \\
\hline
\end{tabular}




\begin{tabular}{|ll|}
\hline Variables & Total patients ( $\boldsymbol{n = 1 9 3 )}$ \\
\hline Unilobar & $43(22.3)$ \\
\hline Bilobar & $150(77.7)$ \\
\hline Baseline serum CEA - no. (\%) & $112(58.0)$ \\
$\leq 200 \mathrm{ng} / \mathrm{mL}$ & $81(42.0)$ \\
\hline$>200 \mathrm{ng} / \mathrm{mL}$ & \\
\hline Baseline serum CA19-9 - no. (\%) & $110(57.0)$ \\
\hline$\leq 200 U / \mathrm{mL}$ & $83(43.0)$ \\
\hline$>200 \mathrm{U} / \mathrm{mL}$ & \\
\hline Targeted therapy - no. (\%) & $152(78.8)$ \\
\hline Yes & $41(21.2)$ \\
\hline No & \\
\hline Outcome of conversion therapy - no. (\%) & $108(56.0)$ \\
\hline Success & $85(44.0)$ \\
\hline Failure
\end{tabular}

\section{Distribution of RAS status in initially unresectable CRLM}

KRAS mutations were found in $47(24.4 \%)$ patients, NRAS mutations were found in only $4(2.07 \%)$ patients, and the remainder of the patients were RAS wild type (Fig. 1A). G12D amino acid substitution was the most common KRAS mutation (36.17\%, 17/47 patients), followed by G12V $(23.40 \%, 11 / 47$ patients) and G13D (17.02\%, 8/47 patients) (Fig. 1B). Furthermore, to investigate the clinicopathological parameters related to RAS mutation in IU-CRLM patients, the patients were stratified into two groups according to RAS status. Clinicopathological characteristics were included in the chi-square test, and the results are shown in Table 2. Preoperative CA19-9 levels over $200 \mathrm{U} / \mathrm{mL}(56.9 \%$ vs. 38.0\%, $P=0.020)$, T4 staging $(66.7 \%$ vs. $43.7 \%, \mathrm{P}=0.005)$ and $\mathrm{N} 1-2$ staging $(96.1 \%$ vs. $81.7 \%, \mathrm{P}=0.012)$ were the clinical factors associated with RAS mutations. However, no significant association was found between RAS mutation and conversion therapy outcome. 
Table 2

Clinical characteristics between RAS wild-type and mutation patients.

\begin{tabular}{|c|c|c|c|}
\hline Variables & Wild-type (n=142) & Mutation-type $(n=51)$ & $P$ value \\
\hline Age & $96(67.6)$ & $33(64.7)$ & 0.706 \\
\hline$\leq 60$ & $46(32.4)$ & $18(35.3)$ & 0.084 \\
\hline$>60$ & $105(76.6)$ & $32(64.0)$ & \\
\hline \multicolumn{4}{|l|}{ Gender - no. (\%) } \\
\hline \multicolumn{4}{|l|}{ Male } \\
\hline Female & $32(23.4)$ & $18(36.0)$ & \\
\hline Primary tumor location a - no. (\%) & & & 0.418 \\
\hline Colon & $95(67.9)$ & $37(74.0)$ & \\
\hline Rectum & $45(32.1)$ & $13(26.0)$ & \\
\hline Primary tumor differentiation ${ }^{b}-$ no. $(\%)$ & & & 0.421 \\
\hline Well or moderate & $106(82.8)$ & $38(77.6)$ & \\
\hline Poor & $22(17.2)$ & $11(22.4)$ & \\
\hline Clinical T staging - no. (\%) & & & 0.005 \\
\hline T1-T3 & $80(56.3)$ & 17 (33.3) & \\
\hline $\mathrm{T} 4$ & $62(43.7)$ & $34(66.7)$ & \\
\hline Clinical N staging - no. (\%) & & & 0.012 \\
\hline No & $26(18.3)$ & $2(3.9)$ & \\
\hline N1-N2 & $116(81.7)$ & $49(96.1)$ & \\
\hline Timing of liver metastases - no. (\%) & & & 0.542 \\
\hline Synchronous & $131(92.3)$ & $49(96.1)$ & \\
\hline Metachronous & $11(7.7)$ & $2(3.9)$ & \\
\hline Number of liver metastases - no. (\%) & & & 0.505 \\
\hline$\leq 10$ & $91(64.1)$ & $30(58.8)$ & \\
\hline$>10$ & $51(35.9)$ & $21(41.2)$ & \\
\hline Maximum size of liver metastases - no. (\%) & & & 0.170 \\
\hline$\leq 6 \mathrm{~cm}$ & $79(55.6)$ & $34(66.7)$ & \\
\hline
\end{tabular}




\begin{tabular}{|c|c|c|c|}
\hline Variables & Wild-type (n=142) & Mutation-type $(n=51)$ & $P$ value \\
\hline$>6 \mathrm{~cm}$ & $63(44.1)$ & $17(33.3)$ & \\
\hline Distribution of liver metastases - no. (\%) & & & 0.593 \\
\hline Unilobar & $33(23.2)$ & $10(19.6)$ & \\
\hline Bilobar & $109(76.8)$ & $41(80.4)$ & \\
\hline Baseline serum CEA - no. (\%) & & & 0.074 \\
\hline$\leq 200 \mathrm{ng} / \mathrm{mL}$ & $77(54.2)$ & $35(68.6)$ & \\
\hline$>200 \mathrm{ng} / \mathrm{mL}$ & $65(45.8)$ & $16(31.4)$ & \\
\hline Baseline serum CA19-9 - no. (\%) & & & 0.020 \\
\hline$\leq 200 \mathrm{U} / \mathrm{mL}$ & $88(62.0)$ & $22(43.1)$ & \\
\hline$>200 \mathrm{U} / \mathrm{mL}$ & $54(38.0)$ & $29(56.9)$ & \\
\hline Targeted therapy - no. (\%) & & & 0.014 \\
\hline Yes & $118(83.1)$ & $34(66.7)$ & \\
\hline No & $24(16.9)$ & $17(33.3)$ & \\
\hline Outcome of conversion therapy - no. (\%) & & & 0.631 \\
\hline Success & $78(54.9)$ & $30(57.6)$ & \\
\hline Failure & $64(45.1)$ & $21(42.4)$ & \\
\hline
\end{tabular}

\section{Association of RAS status with disease early progression}

RAS mutation was significantly related to early disease progression ( $66.7 \%$ vs. $49.3 \%, P=0.033$, Fig. $2 A$ ). In the patients achieving successful conversion outcomes, the early progression rate was higher in RASmutated patients than in those with wild-type RAS ( $53.3 \%$ vs. $24.4 \%, P=0.004$, Fig. $2 B$ ). However, the early progression rate was not significantly different between the RAS mutated and RAS wild-type patients with failed conversion outcomes ( $85.7 \%$ vs. $79.7 \%, P=0.771$, Fig. 2 C). As shown in Table 3 , in the univariate logistic regression analysis, failed conversion therapy (OR= $8.99595 \% \mathrm{Cl} 4.571-17.699, \mathrm{P}<0.001)$, number of liver metastases greater than $10(\mathrm{OR}=1.837,95 \% \mathrm{Cl} 1.018-3.313, \mathrm{P}=0.043)$, bilobar liver metastases $(\mathrm{OR}=2.017,95 \% \mathrm{Cl} 1.015-4.229, \mathrm{P}=0.045)$, and RAS mutation ( $\mathrm{OR}=2.057,95 \% \mathrm{Cl} 1.045-4.015, \mathrm{P}=0.035)$ were significantly related to early disease progression. The multivariate analysis indicated that RAS mutation $(\mathrm{OR}=2.962,95 \% \mathrm{Cl} 1.354-6.478, \mathrm{P}=0.007)$ and failed conversion therapy $(\mathrm{OR}=10.485,95 \% \mathrm{Cl}$ 4.958-22.176, $P<0.001)$ were independent risk factors for early disease progression. 
Table 3

Univariate and multivariate logistic regression analyses of risk factors for early progression.

\begin{tabular}{|c|c|c|c|c|}
\hline \multirow[t]{2}{*}{ Parameters } & \multicolumn{2}{|l|}{ Univariate } & \multicolumn{2}{|l|}{ Multivariate } \\
\hline & OR $(95 \% \mathrm{Cl})$ & $\begin{array}{l}P \\
\text { value }\end{array}$ & OR (95\% Cl) & $\begin{array}{l}P \\
\text { value }\end{array}$ \\
\hline Age, years - no. (\%) & & 0.286 & & \\
\hline$\leq 60$ & Ref & & & \\
\hline$>60$ & $\begin{array}{l}0.721(0.395- \\
1.315)\end{array}$ & & & \\
\hline Sex - no. (\%) & & 0.281 & & \\
\hline Male & Ref & & & \\
\hline Female & $\begin{array}{l}0.697(0.361- \\
1.344)\end{array}$ & & & \\
\hline Primary tumor location - no. (\%) & & 0.237 & & \\
\hline Colon & Ref & & & \\
\hline Rectum & $\begin{array}{l}0.688(0.370- \\
1.278)\end{array}$ & & & \\
\hline Primary tumor differentiation - no. (\%) & & 0.379 & & \\
\hline Well or moderate & Ref & & & \\
\hline Poor & $\begin{array}{l}1.405(0.658- \\
2.999)\end{array}$ & & & \\
\hline Timing of metastasis - no. (\%) & & 0.258 & & \\
\hline Synchronous & Ref & & & \\
\hline Metachronous & $\begin{array}{l}0.497(0.148- \\
1.672)\end{array}$ & & & \\
\hline Number of metastatic tumors - no. (\%) & & 0.043 & & 0.534 \\
\hline$\leq 10$ & Ref & & Ref & \\
\hline$>10$ & $\begin{array}{l}1.837(1.018- \\
3.313)\end{array}$ & & $\begin{array}{l}0.783(0.363- \\
1.692)\end{array}$ & \\
\hline $\begin{array}{l}\text { Distribution of liver metastasis - no. } \\
(\%)\end{array}$ & & 0.045 & & 0.180 \\
\hline Unilobar & & & Ref & \\
\hline Bilobar & $\begin{array}{l}2.017(1.015- \\
4.229)\end{array}$ & & $\begin{array}{l}1.871(0.749- \\
4.671)\end{array}$ & \\
\hline
\end{tabular}




\begin{tabular}{|c|c|c|c|c|}
\hline \multirow[t]{2}{*}{ Parameters } & \multicolumn{2}{|l|}{ Univariate } & \multicolumn{2}{|l|}{ Multivariate } \\
\hline & OR (95\% Cl) & $\begin{array}{l}P \\
\text { value }\end{array}$ & OR (95\% Cl) & $\begin{array}{l}P \\
\text { value }\end{array}$ \\
\hline $\begin{array}{l}\text { Median size of largest liver tumor } \\
\text { (range) }-\mathrm{cm}\end{array}$ & & 0.794 & & \\
\hline$\leq 6$ & Ref & & & \\
\hline$>6$ & $\begin{array}{l}1.080(0.608- \\
1.918)\end{array}$ & & & \\
\hline Clinical T staging - no. (\%) & & 0.617 & & \\
\hline T1-T3 & Ref & & & \\
\hline $\mathrm{T} 4$ & $\begin{array}{l}0.866(0.491- \\
1.525)\end{array}$ & & & \\
\hline Clinical N staging - no. (\%) & & 0.236 & & \\
\hline NO & Ref & & & \\
\hline N1-N2 & $\begin{array}{l}0.605(0.263- \\
1.389)\end{array}$ & & & \\
\hline Serum CEA - no. (\%) & & 0.630 & & \\
\hline$\leq 200 \mathrm{ng} / \mathrm{mL}$ & Ref & & & \\
\hline$>200 \mathrm{ng} / \mathrm{mL}$ & $\begin{array}{l}0.868(0.489- \\
1.541)\end{array}$ & & & \\
\hline Serum CA19-9 - no. (\%) & & 0.340 & & \\
\hline$\leq 200 \mathrm{U} / \mathrm{mL}$ & Ref & & & \\
\hline$>200 U / m L$ & $\begin{array}{l}1.322(0.745- \\
2.348)\end{array}$ & & & \\
\hline Total RAS status - no. (\%) & & 0.035 & & 0.007 \\
\hline Wild type & Ref & & Ref & \\
\hline Mutation & $\begin{array}{l}2.057(1.054- \\
4.015)\end{array}$ & & $\begin{array}{l}2.962(1.354- \\
6.478)\end{array}$ & \\
\hline Targeted therapy - no. (\%) & & 0.276 & & \\
\hline Yes & Ref & & & \\
\hline No & $\begin{array}{l}1.469(0.735- \\
2.936)\end{array}$ & & & \\
\hline $\begin{array}{l}\text { Outcome of conversion therapy - no. } \\
(\%)\end{array}$ & & $<0.001$ & & $<0.001$ \\
\hline
\end{tabular}




\begin{tabular}{|lllll|}
\hline Parameters & Univariate & & Multivariate & \\
\cline { 2 - 4 } & OR $(95 \% \mathrm{Cl})$ & $\begin{array}{c}\boldsymbol{P} \\
\text { value }\end{array}$ & OR $(95 \% \mathrm{Cl})$ & $\begin{array}{c}\boldsymbol{P} \\
\text { value }\end{array}$ \\
\hline Success & Ref & Ref & \\
\hline Failure & $\begin{array}{l}8.995(4.571- \\
17.699)\end{array}$ & $\begin{array}{l}10.485(4.958- \\
\end{array}$ & & $22.176)$ \\
\hline
\end{tabular}

\section{Discussion}

The occurrence and development of CRC metastases involve a number of signalling pathways, such as transforming growth factor $\beta$ (TGF- $\beta$ ), Wnt, Notch, Hedgehog, phosphatidylinositol 3-kinase and protein kinase $B(P I 3 K / A k t)$, nuclear factor kappa light chain enhancer of activated B cells (NF- KB) and microtubule associated protein kinase (MAPK) ${ }^{[28]}$. KRAS mutation is the most common mutated driver gene in CRC, with an incidence of approximately $40 \%{ }^{[29,30]}$. Our study showed the incidence of total RAS mutations in $26.0 \%$ of IU-CRLM patients. There was a significant association between RAS mutation and early progression of CRLM after first-line systemic therapy. The results indicated that RAS mutation IUCRLM represented more malignant biological behaviour than RAS wild-type IU-CRLM.

The epidermal growth factor receptor (EGFR) signalling pathway, which is activated by mutated KRAS, plays a crucial role in CRLM progression. In the EGFR pathway, the RAS protein acts as a gating switch, and the activation of RAS and MEK, downstream molecules of the RAS protein, depends on RAS mutation. Once RAS is mutated, it will constantly activate downstream pathways involving MAPK and PI3K-AKT as well as the downstream transcription factors of these pathways. Ultimately, mutated RAS regulates the expression level of proteins related to tumour invasion and metastasis. ${ }^{[31,32]}$ Animal experiments also confirmed that CRC with mutated KRAS could promote the occurrence of lung metastasis with cells from liver metastases by activating the MAPK pathway. ${ }^{[33]}$ These results suggest that KRAS mutation enhances malignant invasion and metastasis in CRC cells, which accelerates the progression of CRLM. In addition, glycolysis metabolism in cancer cells is elevated by mutated KRAS. ${ }^{[34]}$ Previous studies reported that KRAS mutation was able to upregulate the expression levels of GLUT1, HK and LDH, which increased the process of tumour glucose uptake. Recently, research from Yun et al. revealed an increase in the expression level of GLUT1 and higher glucose uptake in CRC cell lines with mutated KRAS ${ }^{[35,36]}$. Such alterations in metabolism confer CRC cells with a survival advantage, as they can gain long-term survival advantages in low-glucose environments, thereby creating favourable conditions for tumour metastasis.

Interestingly, our results showed that RAS mutation was a risk factor for early progression only in patients with successful conversion therapy outcomes. In fact, in recent years, a growing number of studies have indicated that RAS mutation is a negative prognostic factor for patients with CRLM after surgery. A phase II clinical study from the Medical University of Vienna enrolled 60 patients with initially resectable CRLM, 
all of whom had been administered oxaliplatin combined with bevacizumab before hepatectomy. The results demonstrated that in patients with KRAS mutations, the overall survival (OS) and relapse-free survival (RFS) were shorter. ${ }^{[37]}$ Another study from the M.D. Anderson Cancer Center enrolled a total of 524 CRLM patients who underwent both curative liver section and RAS mutant detection. The results suggested that the median overall survival was remarkably shorter in patients with KRAS codons 12 and 13 mutations than in wild-type patients. ${ }^{[20]} \mathrm{A}$ study conducted by Brudvik KW et al indicated that although the size of tumours was similar, liver metastases with mutational KRAS infiltrated more widely than wild-type metastases, increasing the rate of margin positivity, which may be the leading cause of poor prognosis. ${ }^{[31]}$

However, in patients experiencing conversion therapy failure, tumours may develop acquired resistance during treatment. At present, one of the mechanisms of acquired resistance is secondary mutations in driver genes. In metastatic CRC, gene mutations in RAS/RAF pathways are the most common molecular mechanism causing acquired resistance. ${ }^{[38]}$ Calcagno SR et al found that KRAS G12D mutation could promote proliferation of the intestinal epithelium by constantly activating the MEK-ERK signalling axis in the mouse intestinal epithelium. The results of this study showed that mutations in KRAS and aberrant activation of its downstream signalling pathway participated in the development of acquired resistance in CRC. ${ }^{[32]}$ Since our study failed to conduct dynamic circulating tumour DNA detection, RAS status before first-line systemic therapy may not accurately predict early progression in patients with secondary mutations.

Moreover, in our study, the early progression rate of patients with successful conversion therapy was significantly decreased compared with that of patients experiencing therapy failure. For patients with RAS mutations, the current guidelines recommend that if patients can tolerate treatment, FOLFOXIRI combined with bevacizumab can maximize the efficacy of conversion therapy ${ }^{[39]}$. Additionally, surgeons should ensure adequate liver resection to reduce the rates of positive surgical margins in these patients. Meanwhile, a sufficient number of preoperative chemotherapy cycles and more frequent postoperative follow-up visits may effectively prevent early disease progression.

There are some limitations to this retrospective study. First, the number of included patients may be inadequate, and selection bias may exist. Hence, larger numbers of patients are required for external validation. Second, several biomarkers were identified as crucial prognostic factors for survival and recurrence, including BRAF, PI3K and TP53, which are still under debate ${ }^{[40-42]}$. In this study, we included only RAS in the analysis; future studies should take more gene status into consideration to gain a better understanding of the influence of these biomarkers on early disease progression. The 5-year survival data were unavailable for some patients due to an insufficient follow-up duration. This issue may have led to the underestimation or overestimation of the effect of RAS mutation on conversion therapy outcomes.

\section{Conclusions}


Our study revealed that RAS mutation was a risk factor for early disease progression in patients with IUCRLM after first-line systemic therapy. More attention should be given to treatment decisions for IU-CRLM patients with RAS mutations.

\section{Abbreviations}

\section{IU-CRLM}

Initially unresectable colorectal cancer liver metastases.

CRC

Colorectal cancer.

CRLM

Colorectal cancer liver metastases.

\section{MDT}

Multidisciplinary team.

\section{RECIST}

Response evaluation criteria in solid tumors.

NED

No evidence of disease.

RFA

Radiofrequency ablation.

ORs

Odds ratios.

Cls

Confidence intervals.

MAPK

Microtubule associated protein kinase.

OS

Overall survival.

RFS

Relapsed-free survival.

\section{Declarations}

Ethics approval and consent to participate

All procedures were performed based on the Declaration of Helsinki. The study was approved by the Institutional Research Ethics Committee of Sun Yat-sen University Cancer Center (approval number: B2020-309-01).

Consent for publication 
Not applicable.

\section{Availability of data and materials}

The datasets used and analysed during the current study are available from the corresponding author on reasonable request. The authenticity of this article has been validated by uploading the key raw data onto the Research Data Deposit public platform (www. researchdata.org.cn).

\section{Competing interests}

None of the authors have conflicts of interest or financial ties to disclose.

\section{Funding}

This study was funded by grants from the National Natural Science Foundation of China (no. 82003051 and no. 81772595).

\section{Author's contributions}

DC analysed the patient data and wrote the initial draft of the paper. CL, CZ developed the idea for the study. WLZ collected the data. DC, CL, CZ, ZZP, GC, ZHL and JHP revised the manuscript. JHP and GC provided datasets of patients and designed the study. All authors read and approved the final manuscript.

\section{Acknowledgments}

We greatly appreciate the help from all of our colleagues in the Department of Colorectal Surgery at Sun Yat-sen University Cancer Center who were involved in administering the treatments in the current study.

\section{References}

1. Chen W, Zheng R, Baade PD, et al. Cancer statistics in China, 2015. CA Cancer J Clin. 2016. 66(2): 115-32.

2. Siegel RL, Miller KD, Goding Sauer A, et al. Colorectal cancer statistics, 2020. CA Cancer J Clin. 2020. 70(3): 145-164.

3. Jones RP, Kokudo N, Folprecht G, et al. Colorectal Liver Metastases: A Critical Review of State of the Art. Liver Cancer. 2016. 6(1): 66-71.

4. 4.

5. Adam R, de Gramont A, Figueras J, et al. Managing synchronous liver metastases from colorectal cancer: a multidisciplinary international consensus. Cancer Treat Rev. 2015. 41(9): 729-41.

6. Adam R, De Gramont A, Figueras J, et al. The oncosurgery approach to managing liver metastases from colorectal cancer: a multidisciplinary international consensus. Oncologist. 2012. 17(10): 122539. 
7. Truant $S$, Séquier $C$, Leteurtre $E$, et al. Tumour biology of colorectal liver metastasis is a more important factor in survival than surgical margin clearance in the era of modern chemotherapy regimens. HPB (Oxford). 2015. 17(2): 176-84.

8. Bolhuis K, Kos M, van Oijen M, Swijnenburg RJ, Punt C. Conversion strategies with chemotherapy plus targeted agents for colorectal cancer liver-only metastases: A systematic review. Eur $\mathrm{J}$ Cancer. 2020. 141: 225-238.

9. Leung U, Gönen M, Allen PJ, et al. Colorectal Cancer Liver Metastases and Concurrent Extrahepatic Disease Treated With Resection. Ann Surg. 2017. 265(1): 158-165.

10. Lin J, Peng J, Zhao Y, et al. Early recurrence in patients undergoing curative resection of colorectal liver oligometastases: identification of its clinical characteristics, risk factors, and prognosis. $J$ Cancer Res Clin Oncol. 2018. 144(2): 359-369.

11. Vigano L, Darwish SS, Rimassa L, et al. Progression of Colorectal Liver Metastases from the End of Chemotherapy to Resection: A New Contraindication to Surgery. Ann Surg Oncol. 2018. 25(6): 16761685.

12. Nordlinger B, Guiguet M, Vaillant JC, et al. Surgical resection of colorectal carcinoma metastases to the liver. A prognostic scoring system to improve case selection, based on 1568 patients. Association Française de Chirurgie. Cancer. 1996. 77(7): 1254-62.

13. Kawahara H, Yoshida S, Tohyama Y, Yanagisawa S, Misawa T, Yanaga K. Serum Carcinoembryonic Antigen Levels Before the First Curative Hepatectomy for Metastatic Colorectal Cancer Is a Predictor of Recurrence. Anticancer Res. 2018. 38(9): 5351-5355.

14. Jung SW, Kim DS, Yu YD, Han JH, Suh SO. Risk factors for cancer recurrence or death within 6 months after liver resection in patients with colorectal cancer liver metastasis. Ann Surg Treat Res. 2016. 90(5): 257-64.

15. 15.

16. Amikura K, Akagi K, Ogura T, Takahashi A, Sakamoto H. The RAS mutation status predicts survival in patients undergoing hepatic resection for colorectal liver metastases: The results from a genetic analysis of all-RAS. J Surg Oncol. 2018. 117(4): 745-755.

17. Bissonnette $\mathrm{M}$, Khare $\mathrm{S}$, von Lintig FC, et al. Mutational and nonmutational activation of p21ras in rat colonic azoxymethane-induced tumors: effects on mitogen-activated protein kinase, cyclooxygenase2, and cyclin D1. Cancer Res. 2000. 60(16): 4602-9.

18. Salomon DS, Brandt R, Ciardiello F, Normanno N. Epidermal growth factor-related peptides and their receptors in human malignancies. Crit Rev Oncol Hematol. 1995. 19(3): 183-232.

19. Hemming AW, Davis NL, Kluftinger A, et al. Prognostic markers of colorectal cancer: an evaluation of DNA content, epidermal growth factor receptor, and Ki-67. J Surg Oncol. 1992. 51(3): 147-52.

20. Passot G, Denbo JW, Yamashita S, et al. Is hepatectomy justified for patients with RAS mutant colorectal liver metastases? An analysis of 524 patients undergoing curative liver resection. Surgery. 2017. 161(2): 332-340. 
21. Okuno M, Goumard C, Kopetz S, et al. RAS Mutation is Associated with Unsalvageable Recurrence Following Hepatectomy for Colorectal Cancer Liver Metastases. Ann Surg Oncol. 2018. 25(8): 24572466.

22. Brudvik KW, Jones RP, Giuliante F, et al. RAS Mutation Clinical Risk Score to Predict Survival After Resection of Colorectal Liver Metastases. Ann Surg. 2019. 269(1): 120-126.

23. Therasse P, Arbuck SG, Eisenhauer EA, et al. New guidelines to evaluate the response to treatment in solid tumors. European Organization for Research and Treatment of Cancer, National Cancer Institute of the United States, National Cancer Institute of Canada. J Natl Cancer Inst. 2000. 92(3): 205-16.

24. Loupakis F, Cremolini C, Salvatore L, et al. FOLFOXIRI plus bevacizumab as first-line treatment in BRAF mutant metastatic colorectal cancer. Eur J Cancer. 2014. 50(1): 57-63.

25. Taal W, Brandsma D, de Bruin HG, et al. Incidence of early pseudo-progression in a cohort of malignant glioma patients treated with chemoirradiation with temozolomide. Cancer. 2008. 113(2): 405-10.

26. de Geus-Oei LF, van Laarhoven HW, Visser EP, et al. Chemotherapy response evaluation with FDG-PET in patients with colorectal cancer. Ann Oncol. 2008. 19(2): 348-52.

27. Ackland SP, Jones $M, T u$ D, et al. A meta-analysis of two randomised trials of early chemotherapy in asymptomatic metastatic colorectal cancer. Br J Cancer. 2005. 93(11): 1236-43.

28. Weidle UH, Birzele F, Krüger A. Molecular targets and pathways involved in liver metastasis of colorectal cancer. Clin Exp Metastasis. 2015. 32(6): 623-35.

29. Van Cutsem E, Köhne CH, Láng I, et al. Cetuximab plus irinotecan, fluorouracil, and leucovorin as firstline treatment for metastatic colorectal cancer: updated analysis of overall survival according to tumor KRAS and BRAF mutation status. J Clin Oncol. 2011. 29(15): 2011-9.

30. Bokemeyer C, Bondarenko I, Hartmann JT, et al. Efficacy according to biomarker status of cetuximab plus FOLFOX-4 as first-line treatment for metastatic colorectal cancer: the OPUS study. Ann Oncol. 2011. 22(7): 1535-1546.

31. Leicht DT, Balan V, Zhu J, et al. MEK-1 activates C-Raf through a Ras-independent mechanism. Biochim Biophys Acta. 2013. 1833(5): 976-86.

32. Calcagno SR, Li S, Colon M, et al. Oncogenic K-ras promotes early carcinogenesis in the mouse proximal colon. Int J Cancer. 2008. 122(11): 2462-70.

33. Urosevic J, Garcia-Albéniz X, Planet E, et al. Colon cancer cells colonize the lung from established liver metastases through p38 MAPK signalling and PTHLH. Nat Cell Biol. 2014. 16(7): 685-94.

34. Pupo E, Avanzato D, Middonti E, Bussolino F, Lanzetti L. KRAS-Driven Metabolic Rewiring Reveals Novel Actionable Targets in Cancer. Front Oncol. 2019. 9: 848.

35. Yun J, Rago C, Cheong I, et al. Glucose deprivation contributes to the development of KRAS pathway mutations in tumor cells. Science. 2009. 325(5947): 1555-9.

36. Kasprzak A. Insulin-Like Growth Factor 1 (IGF-1) Signaling in Glucose Metabolism in Colorectal Cancer. Int J Mol Sci. 2021. 22(12). 
37. Stremitzer S, Stift J, Gruenberger B, et al. KRAS status and outcome of liver resection after neoadjuvant chemotherapy including bevacizumab. Br J Surg. 2012. 99(11): 1575-82.

38. Bouchahda M, Karaboué A, Saffroy R, et al. Acquired KRAS mutations during progression of colorectal cancer metastases: possible implications for therapy and prognosis. Cancer Chemother Pharmacol. 2010. 66(3): 605-9.

39. Tomasello G, Petrelli F, Ghidini M, Russo A, Passalacqua R, Barni S. FOLFOXIRI Plus Bevacizumab as Conversion Therapy for Patients With Initially Unresectable Metastatic Colorectal Cancer: A Systematic Review and Pooled Analysis. JAMA Oncol. 2017. 3(7): e170278.

40. Sanz-Garcia E, Argiles G, Elez E, Tabernero J. BRAF mutant colorectal cancer: prognosis, treatment, and new perspectives. Ann Oncol. 2017. 28(11): 2648-2657.

41. Liao X, Lochhead P, Nishihara R, et al. Aspirin use, tumor PIK3CA mutation, and colorectal-cancer survival. N Engl J Med. 2012. 367(17): 1596-606.

42. Carethers JM, Jung BH. Genetics and Genetic Biomarkers in Sporadic Colorectal Cancer. Gastroenterology. 2015. 149(5): 1177-1190.e3.

\section{Figures}

A Constistuion of total RAS status

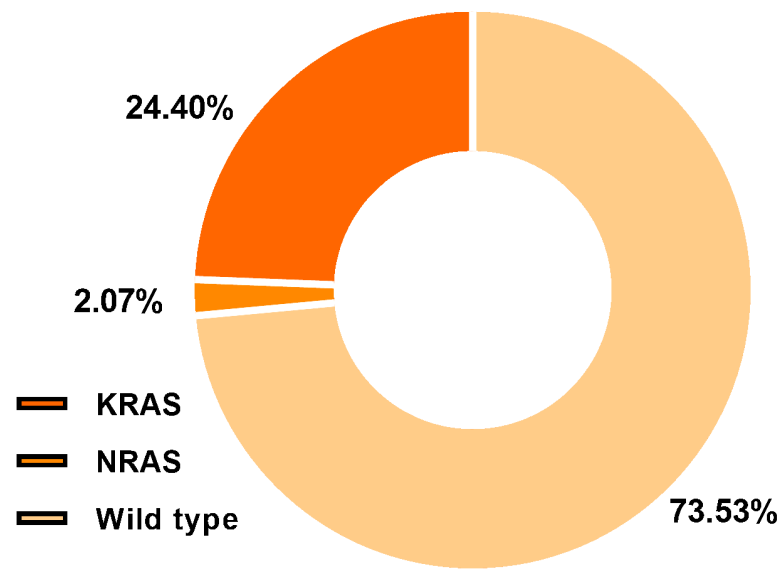

B Types of KRAS mutation

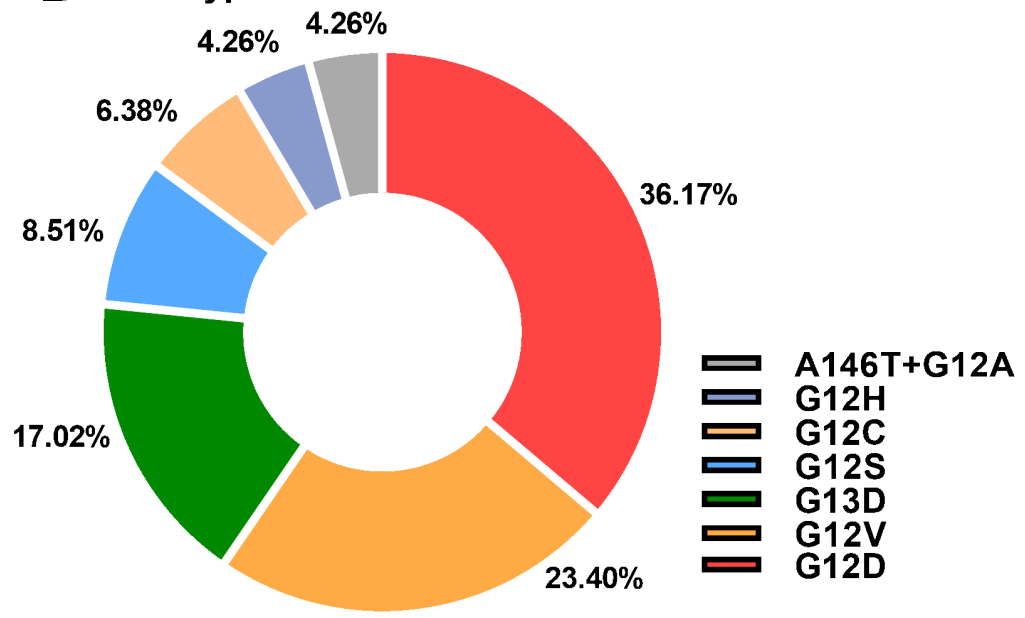

\section{Figure 1}

Distribution of RAS status in IU-CRLM patients. (A) Constitution of total RAS status. (B) Percentages of the 7 different types of KRAS mutations. 
A

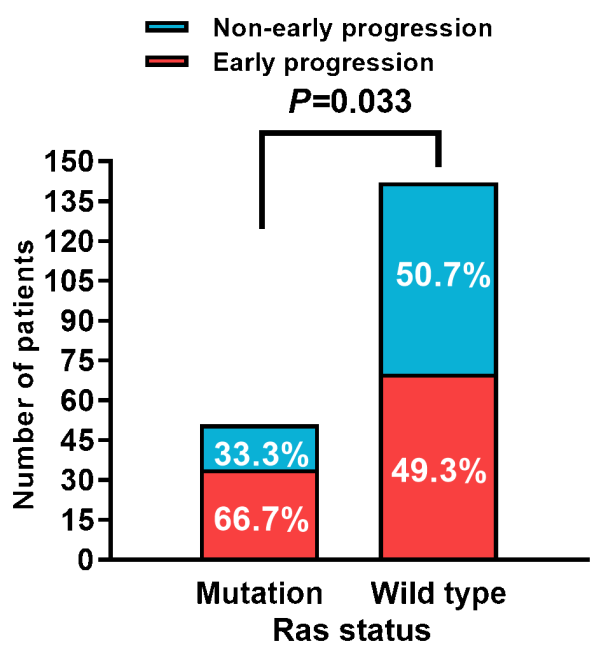

B

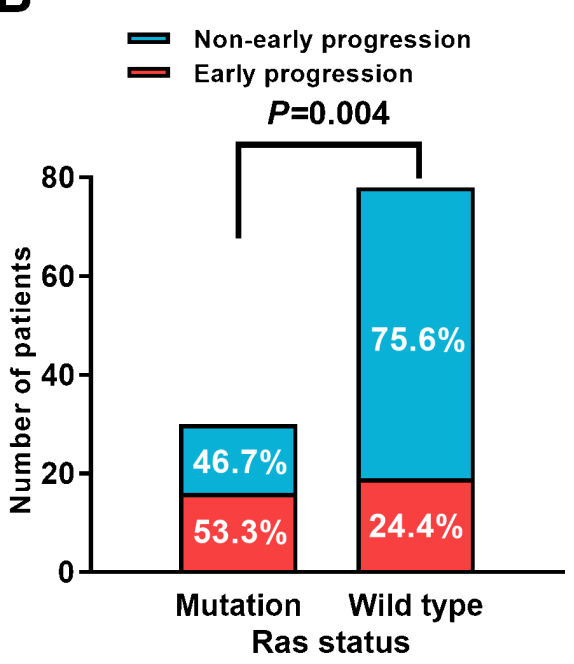

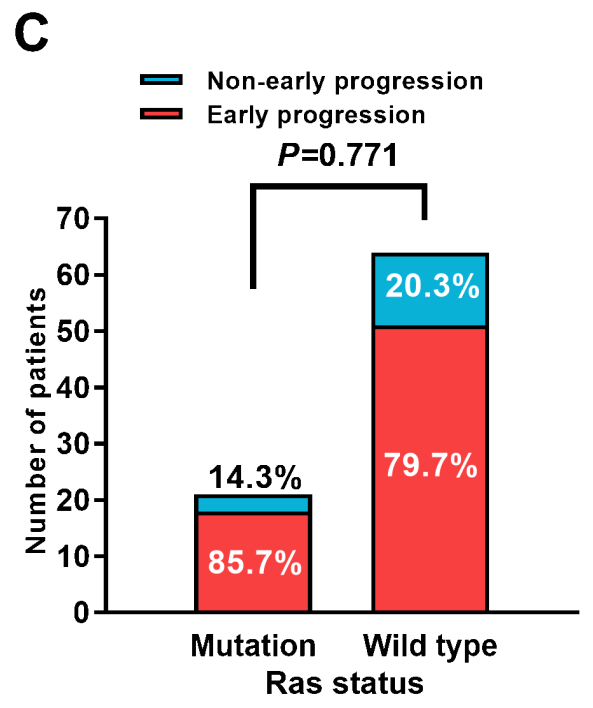

\section{Figure 2}

Association between RAS status and early progression. (A) Mutated RAS was significantly related to early disease progression among all groups. (B) Mutated RAS was associated with early progression in patients with successful conversion therapy outcomes. (C) Early progression was independent of RAS status in patients experiencing conversion therapy failure. 